\title{
A systematic review of oil tanker truck disasters: Identifying prevention targets
}

\author{
Clifton Ewbank ${ }^{a, *}$, Shailvi Gupta ${ }^{b}$, Barclay T. Stewart ${ }^{c, d}$, \\ Adam L. Kushner ${ }^{e, f, g, h}$, Anthony Charles ${ }^{i, j}$ \\ a Department of Surgery, UCSF-East Bay, 1411 East 31st St. QIC22134, Oakland, CA 94602, United States \\ ${ }^{\mathrm{b}} \mathrm{R}$ Adams Cowley Shock Trauma Center, University of Maryland, Surgeons OverSeas, United States \\ ${ }^{\mathrm{c}}$ Department of Surgery, University of Washington, Seattle, WA, United States \\ d Department of Interdisciplinary Health Sciences, Stellenbosch University, Cape Town, South Africa \\ e Surgeons OverSeas (SOS), United States \\ ${ }^{\mathrm{f}}$ Department of International Health, Johns Hopkins Bloomberg School of Public Health, United States \\ ${ }^{g}$ Department of Surgery, Columbia University, Department of Surgery, Columbia University, United States \\ ${ }^{\mathrm{h}}$ Department of Surgery, USUHS, United States \\ ${ }^{\mathrm{i}}$ The University of North Carolina School of Medicine, United States \\ ${ }^{j}$ Gillings School of Global Public Health, University of North Carolina, NC, United States
}

\section{A R T I C L E I N F O}

Article history:

Received 3 August 2018

Accepted 13 December 2018

Keywords:

Global surgery

Oil tanker

Burn

Resource allocation

Haddon matrix

\section{A B S T R A C T}

Introduction: Oil tanker truck disasters have been reported worldwide; however, the circumstances, causes, and health effects of these disasters have not been described. To address this gap, we performed a systematic review using PRISMA criteria to better understand this public health problem and identify prevention targets.

Methods: The academic and lay literatures were systematically searched for terms related to oil tanker truck disasters. Reports about civilian oil tanker truck disasters that occurred from 1997-2017 were included. Details about the disasters were summarized, including circumstances, identifiable causes, and health effects.

Results: The search yielded 4713 Nexis Uni articles, 199 Google results, and one PubMed article; 951 records met inclusion criteria, describing 224 oil tanker truck explosions or fires. At least 2909 people died as a result of these disasters, and 3038 additional people were hospitalized. Almost all deaths (94\%) occurred in low- and low-middle-income countries (LMIC). This may largely be due to scooping- the practice of collecting spilled oil from disabled tanker trucks for use or resale. Using the Haddon matrix, potential targets for future disaster prevention were identified.

Conclusions: These data highlight the circumstances, causes, and health burden related to oil tanker truck disasters. Most began as collisions or rollovers, but nearly half of the fatalities involved scooping. The findings suggest opportunities to promote road safety, improve scene safety and security protocols used by drivers and first responders, and promote public understanding of the dangers of scooping to prevent mass casualty disasters from disabled tanker trucks, particularly in LMIC.

\footnotetext{
* Corresponding author.

E-mail address: cliffewbank@gmail.com (C. Ewbank).

https://doi.org/10.1016/j.burns.2018.12.010
} 


\section{Introduction}

Explosions and fires related to tanker trucks carrying oil and oil byproducts are dangerous and occur globally. Although these disasters are rare, a single explosion can injure a large number of people at once, and the deaths from both acute and delayed complications often number in the hundreds [1]. Drivers, bystanders, and first responders surrounding the tanker truck are all at risk. Based on the few widely publicized disasters, it would appear that there is an increased propensity for oil tanker truck explosions to occur in low and middle-income countries. This may be attributable to poor road safety and bystander practices [2-7]. However, no formal review of the literature has been published to date, and thus little is known these disasters.

Given the lack of knowledge regarding the circumstances, causes, and resulting health burden related to oil tanker truck disasters, we sought to systematically search the academic and lay literatures to better understand these disasters and identify prevention targets Diagram 1.

\section{Materials and methods}

The academic and lay literatures were systematically searched according to PRISMA criteria using PubMed, World Health
Organization (WHO) Global Health Library, Google, and Nexis Uni Academic databases (Appendix A). The latter contains print media, newspapers, radio transcripts, blogs and legal sources from around the world [8]. The search included database specific language and terms for (oil tanker and truck) and (explosion or fire). Records that met the following criteria were included: (i) the record documented a disaster, defined as involving an oil tanker truck fire or explosion; and (ii) the record was published between January 1, 1997 and August 14, 2017 in order to capture a 20-year span Fig. 1.

The records that returned from the search were screened for relevance and inclusion criteria. Corresponding reports for records that met inclusion criteria were reviewed in full for redundancy and information regarding the circumstances of the disaster, potential causes, and the number of people injured, hospitalized, or killed (Table 1). To reduce reporting bias, non-English reports were included and translated with Google Translate (Google Inc., USA).

\section{Data extraction and reporting}

Information from the reports was extracted for individual disasters and described using Excel 2011 (Microsoft Corp., USA). Common themes identified by the search were further described with illustrative examples. When there was variation across reports in the number of reported injured or killed, the highest number reported or documented by the latest
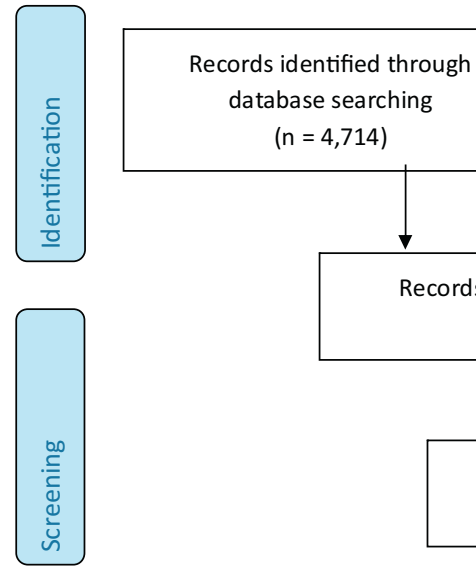

Records after duplicates removed $(n=951)$
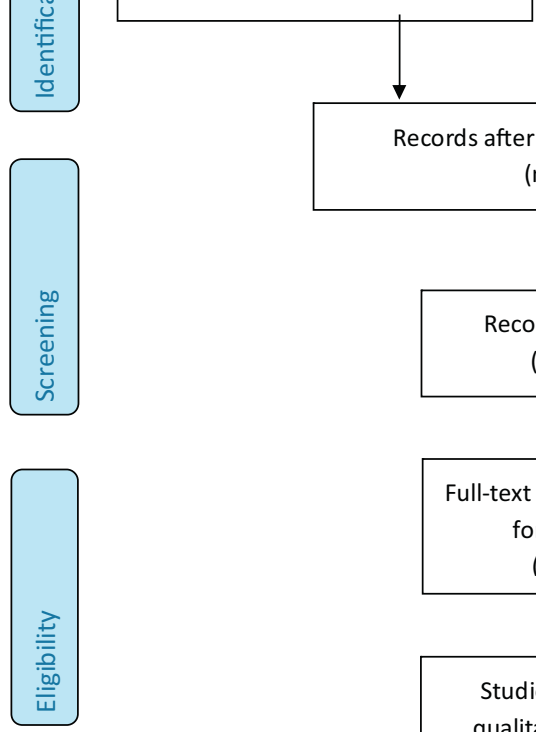

other sources $(n=199)$
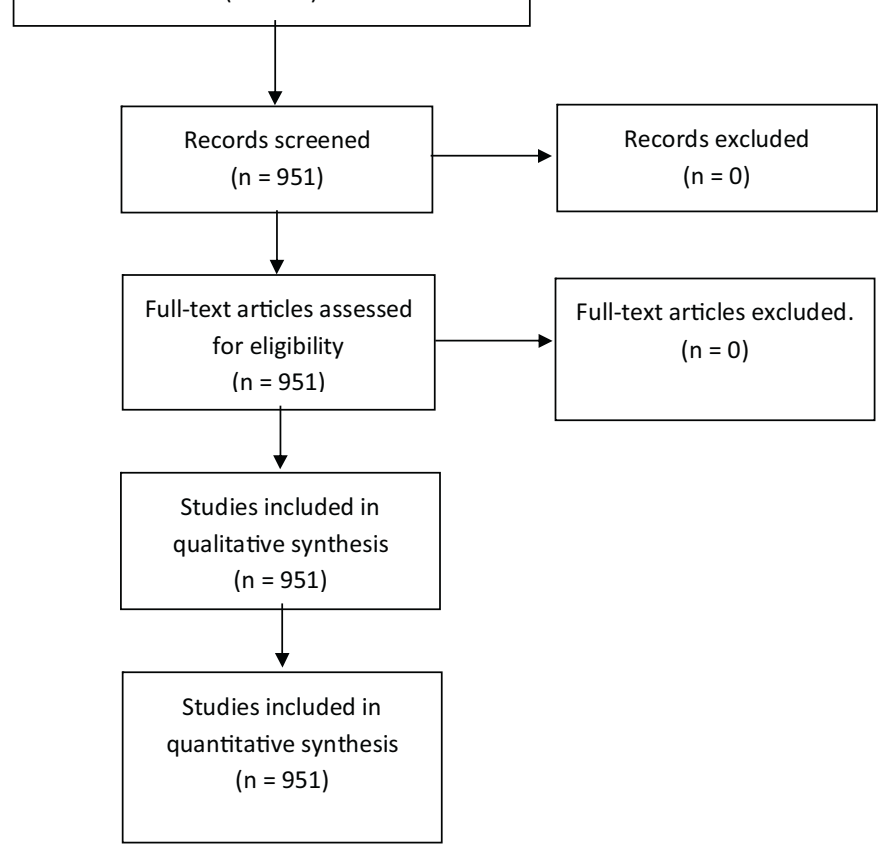

Additional records identified

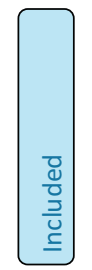

Diagram 1 - PRISMA Flowchart. 


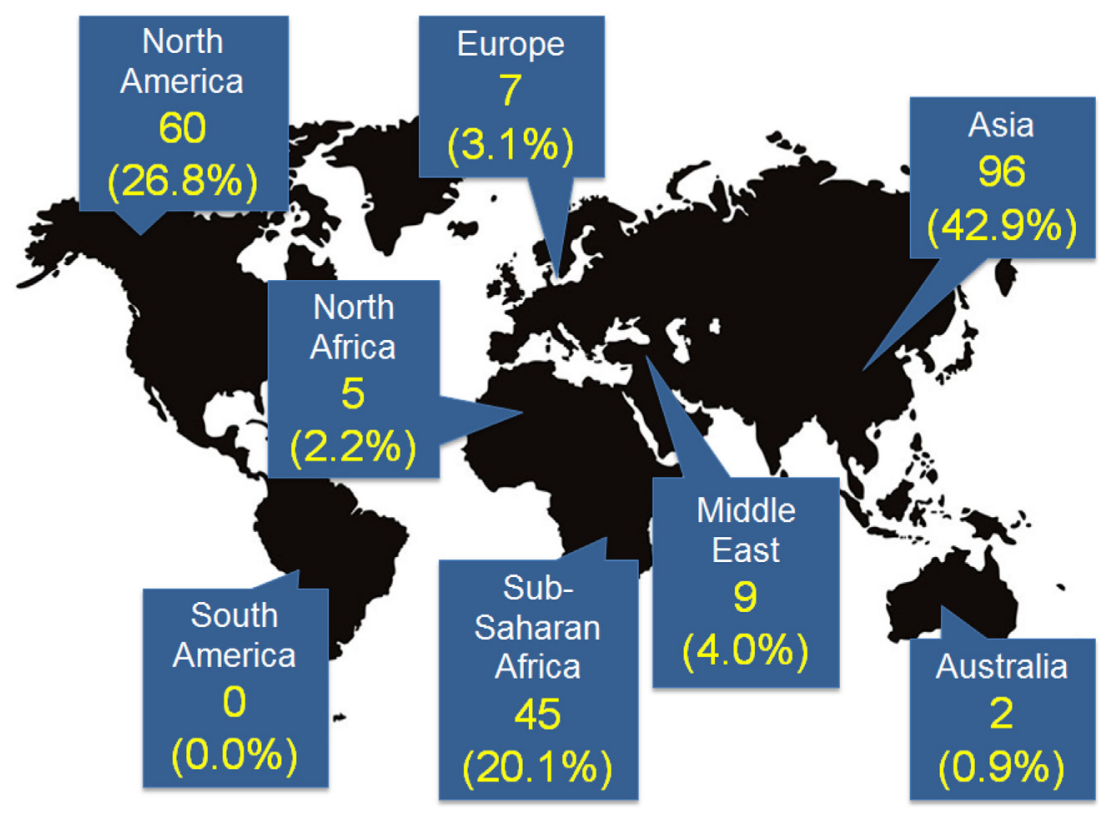

Fig. 1 - Distribution of oil tanker truck disasters by region.

source was used for statistical analysis to account for updated reports, which typically identified additional casualties as information regarding the disaster improved. The findings were reported both in aggregate and according to World Bank Country and Lending Groups (The World Bank, 2017). For accuracy, the full range in the number of casualties reported after each reported explosion was recorded in the database. Themes that emerged from the disasters were classified and illustrative commonalities and potential targets for primary and secondary prevention were described. Finally, a Haddon matrix was applied to evaluate possible factors at various phases of oil tanker disasters that could be targeted with specific strategies for prevention or improved management.

\section{Results}

\section{Systematic search and epidemiology}

The initial search yielded 4713 Nexis Uni articles, 199 Google results, and one PubMed article. There were no results from the search of the WHO Global Health Library. All records were screened for relevance. Nine-hundred and thirty-two records met inclusion criteria and were reviewed. After removing redundant reports, 224 oil tanker truck disasters were described. Of these, 155 disasters (69.2\% of disasters) occurred in five countries: the United States (54 disasters, $24.1 \%$ ), Pakistan (37 disasters, 16.5\%), Nigeria (27 disasters, 12.1\%), India (23 disasters, 10.3\%), and Afghanistan (14 disasters, 6.3\%). The remaining 69 disasters took place in 33 other nations (Table 1).

\section{Causes of oil tanker disasters}

Disasters were reported as "fire" or "explosion" without explanation of cause in 34 disasters (15.2\% of disasters). The underlying cause in the remaining 190 disasters was most commonly reported as collision with commercial or industrial truck (33 disasters, $14.7 \%$ of disasters), rollover without scooping (29 disasters, 12.9\%), collision with a passenger automobile (21 disasters, 9.4\%), routine maintenance (14 disasters, $6.3 \%)$, and rollover followed by scooping (13, 5.8\%). The remaining causes of multiple disasters included fuel transfer from reservoir to oil tanker, oil tanker collision with train, terrorist attack without scooping, collision with a building, collision with another oil tanker, suicide bombing, crash into ravine, and collision with an elephant. Reported causes of oil tanker disasters are described in Table 4.

\section{Scooping}

Scooping played a role in many of the most morbid disasters identified in this study. Characteristics of disasters with scooping included train collision, auto collision, terrorist attack, and selling fuel from a truck illegally. Overall, scooping was responsible for 857 injuries (28.2\% of all injuries) and 1318 deaths ( $45.3 \%$ of all deaths), and was exclusively reported in low- and lower-middle-income countries (LMIC). Eighteen disasters were precipitated by scooping ( $8.0 \%$ of the worldwide total). However, these disasters were the only ones reported in Ghana, Benin, and South Sudan, all of which began with rollovers, as well as Mozambique, where a disaster was precipitated by the driver selling fuel illegally from the truck. The remainder took place in Kenya, Tanzania, Nigeria, Uganda, Pakistan, and Afghanistan, with a variety of inciting causes.

\section{Morbidity and mortality}

The highest numbers of reported injuries were in North Korea (1300 injuries, 42.8\%), Pakistan (254 injuries, 8.4\%), 
Table 1 - Distribution of oil tanker disasters, deaths, injuries, and media reports by country.

\begin{tabular}{|c|c|c|c|c|}
\hline Country & Number of disasters & Deaths & Injuries & Resources \\
\hline Afghanistan & 14 & 187 & 149 & 52 \\
\hline Algeria & 1 & 21 & 13 & 1 \\
\hline Australia & 2 & 4 & 0 & 4 \\
\hline Bangladesh & 1 & 0 & 0 & 1 \\
\hline Benin & 1 & 60 & 80 & 2 \\
\hline Canada & 6 & 10 & 15 & 27 \\
\hline China & 6 & 39 & 55 & 33 \\
\hline Croatia & 1 & 1 & 0 & 1 \\
\hline DRC & 1 & 230 & 110 & 55 \\
\hline Egypt & 1 & 18 & 20 & 2 \\
\hline Ghana & 1 & 25 & NR & 2 \\
\hline Hong Kong & 1 & 0 & 3 & 2 \\
\hline India & 23 & 196 & 37 & 34 \\
\hline Indonesia & 1 & 10 & NR & 1 \\
\hline Iraq & 3 & 33 & 60 & 6 \\
\hline Ireland & 2 & 1 & 0 & 2 \\
\hline Japan & 2 & 1 & 3 & 2 \\
\hline Jordan & 2 & 4 & 9 & 11 \\
\hline Kenya & 9 & 223 & 172 & 31 \\
\hline Libya & 1 & 0 & 0 & 1 \\
\hline Mozambique & 1 & 80 & 110 & 4 \\
\hline N. Korea & 1 & 161 & 1300 & 12 \\
\hline Nepal & 1 & 3 & 0 & 1 \\
\hline Nigeria & 27 & 645 & 250 & 100 \\
\hline Oman & 1 & 1 & 0 & 1 \\
\hline Pakistan & 37 & 599 & 254 & 305 \\
\hline Philippines & 2 & 16 & 0 & 7 \\
\hline Rwanda & 1 & 3 & 0 & 2 \\
\hline Saudi Arabia & 2 & 23 & 113 & 4 \\
\hline Singapore & 1 & 7 & NR & 1 \\
\hline S. Sudan & 1 & 203 & 115 & 35 \\
\hline Tanzania & 2 & 8 & 19 & 3 \\
\hline Thailand & 6 & 9 & 6 & 7 \\
\hline Tunisia & 1 & 6 & 0 & 1 \\
\hline U.S. & 54 & 46 & 132 & 188 \\
\hline Uganda & 2 & 35 & 2 & 3 \\
\hline U.K. & 3 & 1 & 0 & 3 \\
\hline Ukraine & 1 & 0 & 0 & 1 \\
\hline Yemen & 1 & 0 & 11 & 3 \\
\hline Total & 224 & 2909 & 3038 & 951 \\
\hline
\end{tabular}

NR-Not reported.

Nigeria (250 injuries, 8.2\%), Kenya (172 injuries, 5.7\%), Afghanistan (149 injuries, 4.9\%), and the U.S (132 injuries, $4.3 \%)$.

In total, at least 2909 people died from oil tanker truck disasters. Mortality for oil tanker disasters was highest in Nigeria (645 deaths, 22.2\%), Pakistan (599 deaths, 20.6\%), Democratic Republic of the Congo (230 deaths, 7.9\%), India (196 deaths, 6.7\%), Afghanistan (187 deaths, 6.4\%), and North Korea (161 deaths, 5.5\%).

\section{Illustrative examples}

During review of the reports, three important themes emerged as potential targets to better prevent and/or manage oil tanker disasters: improved road safety, elimination of scooping, and enhanced post-crash care (Table 5).

The role of road safety in oil tanker disasters was demonstrated in an incident in Pakistan on January 17, 2015, in which an oil tanker crossed into an opposing lane of highway traffic and collided with a bus overcrowded with passengers, many of whom were sitting on its roof, resulting in a larger number of unrestrained victims. At least 67 people died in this collision, and more were injured [9]. Potential prevention targets include medians on high-risk roads, policies regarding overcrowding, and enforcement of safety regulations for truck drivers (e.g., maintenance of certification, mandatory sleep intervals) Another example of road safety as a factor in these disasters was a collision on November 4, 2000, in Ibadan, Nigeria. An oil tanker truck driver was unable to brake in time for a traffic slowdown, which led to a collision and massive explosion. After, bystanders accused police of soliciting bribes to permit passage, ultimately forcing the first responders to evacuate the area without securing the scene or adequately caring for the injured. The scene was unable to be cleared for days after the collision [10]. Potential targets for 
Table 2 - Distribution of oil tanker truck disasters, deaths, injuries, and media reports in low- and lower-middle-income countries.

\begin{tabular}{|c|c|}
\hline Country & Number of $d$ \\
\hline Afghanistan & 14 \\
\hline Bangladesh & 1 \\
\hline Benin & 1 \\
\hline Algeria & 1 \\
\hline Australia & 2 \\
\hline DRC & 1 \\
\hline Egypt & 1 \\
\hline Ghana & 1 \\
\hline India & 23 \\
\hline Indonesia & 1 \\
\hline Kenya & 9 \\
\hline Mozambique & 1 \\
\hline N. Korea & 1 \\
\hline Nepal & 1 \\
\hline Nigeria & 27 \\
\hline Oman & 1 \\
\hline Pakistan & 37 \\
\hline Philippines & 2 \\
\hline Rwanda & 1 \\
\hline S. Sudan & 1 \\
\hline Tanzania & 2 \\
\hline Tunisia & 1 \\
\hline Uganda & 2 \\
\hline Ukraine & 1 \\
\hline Yemen & 1 \\
\hline Total & 134 \\
\hline
\end{tabular}

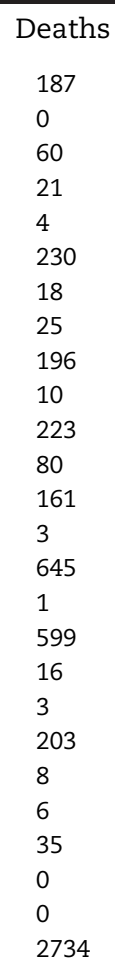

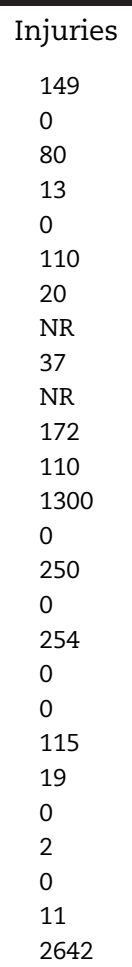

Resources

NR-Not reported.

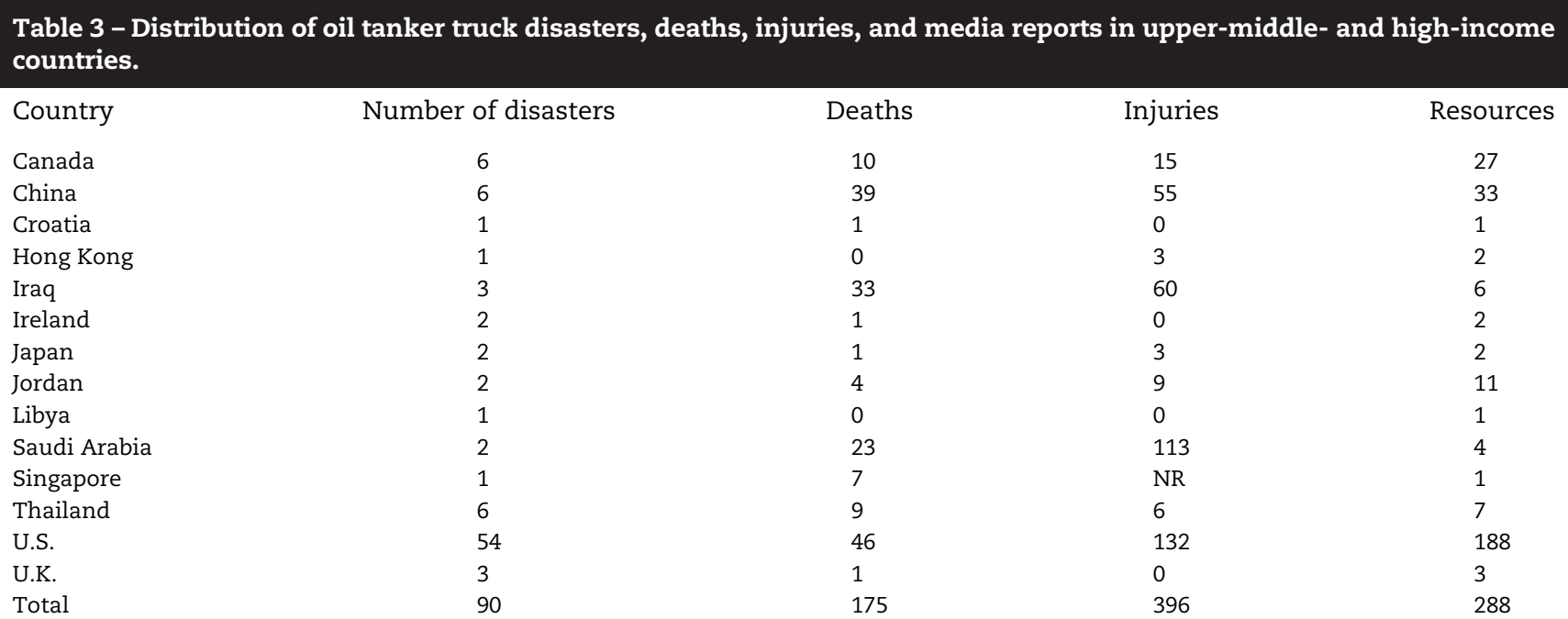

NR-Not reported.

prevention in this case include mandatory commercial truck inspections and servicing to prevent issues like brake failure, as well as improved post-crash care, as discussed further below. These disasters may have been prevented by a number of potential general strategies described in the WHO Global Status Report on Road Safety 2015. These include:

- Changing road user behavior (e.g. reducing speed, reducing drunk/drug-driving, reducing distracted driving)
- Making cars and roads safer (e.g. enforcing United Nations minimum vehicle safety standards, protections for pedestrians/cyclists/motorcyclists).

- Improving post-crash care (e.g. universal emergency numbers, centralized emergency dispatch, lay pre-hospital provider training, emergency specialists at healthcare facilities, trauma care quality improvement programs)

- Improvinglegislation and enforcement related to the above items [11] 
As an example of the contribution of scooping to oil tanker disasters, on July 3, 2010 in South Kivu Province, in the Democratic Republic of the Congo, an oil tanker rolled over and was disabled, spilling fuel onto the ground. Local residents, many of them women and children, approached to scoop fuel from the vehicle. One bystander was smoking a cigarette, which sparked a massive explosion and fire that engulfed those near the truck [6]. Drivers should be educated on scene control and provided with the equipment necessary to communicate with bystanders, blockade the area until additional assistance arrives, contain spillage, and extinguish fire.

Finally, the effects of inadequate first response on burn mortality were demonstrated in North Korea on April 22, 2004 in a remote area near Ryongchon. A train believed to be carrying both passengers and freight collided with an oil tanker truck, resulting in 161 deaths, and more than 1300 injured people. Communications to emergency services were not available, first responders were late to arrive, and the trauma system was ill-equipped to care for the casualties. Ultimately, aid workers were allowed to enter and help the victims, but little additional information was made available by the North Korean authorities [7]. Trauma systems in many LMIC are poorly organized, underfunded, and lack capacity to cope with the baseline burden of injury, much less surge to meet the needs of such disasters [12]. There are examples of training commercial drivers (e.g., truck, minibus, and taxi drivers) to perform the duties of first responders (e.g., scene control, extraction, first aid) in countries without formal emergency medical service [13,14]. Further, with better organization and implementation of low-cost capacity to care for the injured in LMIC, markedly better outcomes could be obtained [15].

\section{Discussion}

Oil tanker truck disasters cause considerable health burden worldwide, particularly in LMIC, much of which is preventable and attributable to scooping, a practice responsible for nearly half of the deaths and over one quarter of related injuries. Although this review identified only 224 oil tanker disasters over 20 years, there was a mean of 9.6 deaths and 12.3 injuries requiring hospitalization per disaster. These figures are even more concerning in LMIC, where there was a mean of 20.4 deaths and 19.7 serious injuries per disaster, despite only representing $60 \%$ of total disasters reported (Table 2). This is in stark contrast to the figures in upper-middle- and high-income countries (HIC), which were 1.9 deaths and 4.4 serious injuries per disaster (Table 3 ). These reports provide several modifiable risk factors as targets for disaster prevention, including: improving road safety, eliminating scooping, and enhancements to both lay and formal post-crash response.

Using a Haddon matrix applied to the illustrative data, these targets for prevention were apparent (Table 5). The Pakistan disaster demonstrated that pre-event agent and host factors related to road safety such as dangerous driving and overfull buses should be addressed. There is an initiative in Nigeria wherein the Federal Road Safety Corps is undergoing a nationwide effort to reduce traffic injuries and fatalities by $50 \%$ from 2010 to 2020 through increased road and vehicle regulations [16]. This initiative would also potentially address post-event factors such as victim recovery and transportation to hospitals, which were both impeded in the Ibadan, Nigeria disaster [10]. Finally, increased attention to corporate responsibility has led to lawsuits in cases of possible negligence by overseas entities, as evidenced by the government of Pakistan filing suit against the company managing an overturned tanker in a 2017 disaster. The government alleged that the tanker did not have the appropriate number of axles for the load it was carrying, which may have contributed to the rollover and subsequent explosion. Ongoing efforts such as these in both high income countries and LMIC should be examined in greater detail for evidence of effectiveness and scaled to improve global prevention of oil tanker disasters.

The role of road safety in preventing oil tanker disasters is supported by the United Nations 2030 Agenda for Sustainable Development, in which Sustainable Development Goal 3.6 states:

By 2020, halve the number of global deaths and injuries from road traffic accidents.

In addition to national safety campaigns such as that in Nigeria, 17 nations have enacted stricter road safety legislation on behalf of 409 million people since the new United Nations Agenda was codified in 2015. These laws address five key indicators of best practice: speeding, drunk driving, helmet use, seat belt use, and appropriate child restraints [11]. While speeding, drunk driving, and seat belt use directly impact the safety of the oil tanker truck and the drivers, all of these indicators affect the passengers in other vehicles who represent many of the casualties in this study.

The most significant contributing factor to both morbidity and mortality in our analysis was scooping. This is largely driven by underlying social environment factors during the event phase, in which a rare opportunity to gather spilled fuel may vastly improve one's personal and family circumstances through the use or sale of reclaimed fuel. According to Onuoha, a political scientist at the University of Nigeria, the victims of petroleum-related disasters are largely women, partially due to the prominent role of women in seeking fuel, be it firewood, kerosene or petrol to cook and provide heating for the home in low- and middle-income countries. This pressure and the allure of free fuel drive the poorest people in oil-rich regions to engage in high-risk practices such as poaching oil from underground lines and oil tanker trucks, often with disastrous consequences [2]. These factors combined, and echoed throughout many LMIC, result in a higher number of female victims of burn disasters [18]. To illustrate this conundrum, an editorial from a Lagos newspaper offers a local woman's comments, "If we don't scoop from here, hunger will kill us. If we die from explosion here, it is still death out of want. We might as well stay here, scoop and hope to survive." In a related discussion, Carlson and colleagues described the tragic loss of life and injuries caused by scavenging fuel from pipelines in sub-Saharan Africa. Similar to scooping in the present study, hundreds of people were injured or killed attempting to poach a valuable local resource from damaged pipelines [19]. While this suggests a larger problem with income inequality and poverty in the region, it also represents an opportunity to protect at-risk populations from the risks of scooping and 
Table 4 - Distribution of oil tanker truck disasters by reported cause.

Cause of disaster

Number of incidents

Fire of unknown cause

Collision with truck(s)

Rollover

Collision with auto(s)

Collision with bus

Maintenance (e.g. cleaning, welding, etc.)

Rollover followed by scooping

Fuel transfer from reservoir

Collision with train

Terrorist attack on tanker

Collision with building(s)

Collision with other tanker

Suicide bomber driving tanker

Fuel transfer from other tanker

Drove into ravine

Collision with bridge

Vandalism

Other followed by scooping ${ }^{\mathrm{a}}$

Other without scooping ${ }^{\mathrm{b}}$

Total

34
33
29
21
21
14
13
8
7
7
6
5
4
3
3
2
2
5
7
224

a Includes after train collision, auto collision, terrorist attack, selling fuel from truck illegally, and scooping from undamaged vehicle.

b Includes explosion after fall from overpass, collision with refinery, collision with storage tank, collision with power station, and collision with elephant.

insecure oil transport. In addition to addressing the underlying socioeconomic circumstances driving this behavior, other interventions might include health and safety education efforts directed towards those living along the major transport routes. The benefits of such efforts have been demonstrated in Dar es Salaam, Tanzania, where implementation of traffic calming measures and sidewalk barriers combined with road safety education markedly reduced school area traffic casualties from nine in the year before the program to one the year following. These measures are relatively low cost and high yield.

Limitations of emergency medical response in the postevent period were seen in the North Korean disaster, largely due to bureaucratic bottlenecks, which included the government North Korea waiting two days to acknowledge that the disaster had occurred [7]. Civilians have acted to alleviate the burden of emergency transport in similar circumstances in South Sudan, utilizing a UNICEF-funded program to equip motorbikes with ambulance sidecars to transport pregnant woman across rough roads to hospitals [17]. Efforts to formally train lay civilians to provide more extensive pre-hospital care have also been successful, as demonstrated in the training of commercial truck drivers in Ghana and lay providers in North Iraq and Cambodia, with marked improvements in trauma mortality from 40\%-14.9\% (95\% CI 17.2-33.0\% difference) over the three-year period of the latter study $[13,14]$. However, even once patients are able to be transported from the disaster scene, further barriers to care were noted in our study in multiple instances. The lack of adequate trauma systems in LMIC contributes to a significant disparity in morbidity from disasters like those described here [12,15]. It is estimated that if LMIC could establish trauma systems comparable to those in high-income countries, over 2 million lives and $\$ 1$ trillion could be saved annually [15]. Responses to this observation include the national effort in Pakistan to expand specialty burn centers, in part to accommodate the massive burn care requirement of victims from these disasters [21]. While such specialized burn care is desirable, in austere settings, even layperson training in local wound care with simple open dressings and improved nutrition with affordable adjuncts can improve outcomes among patients with burns to $<40 \%$ total body surface area [22,23]. Such interventions might allow

Table 5 - Haddon matrix applied to the problem of oil tanker truck disasters.

\begin{tabular}{|c|c|c|c|c|}
\hline Phase & Host & Agent & Physical environment & Social environment \\
\hline $\begin{array}{l}\text { Pre- } \\
\text { event }\end{array}$ & $\begin{array}{l}\text { - Driver } \\
\text { - Maintenance crew }\end{array}$ & $\begin{array}{l}\text { - Speeding truck } \\
\text { - Wrong number of axles } \\
\text { - Momentum of vehicle } \\
\text { - Surrounding buildings } \\
\text { - Train } \\
\text { - Welding torch } \\
\text { - Vehicle carrying both fuel } \\
\text { and passengers }\end{array}$ & $\begin{array}{l}\text { - Poor roads } \\
\text { - Traffic congestion } \\
\text { - Police checkpoints } \\
\text { - Crowded buildings } \\
\text { - Ravines } \\
\text { - Bridges }\end{array}$ & $\begin{array}{l}\text { - Poverty provoking scooping } \\
\text { - Lack of regulation } \\
\text { - Illegal fuel market } \\
\text { - Terrorism } \\
\text { - Corruption }\end{array}$ \\
\hline Event & $\begin{array}{l}\text { - Bystanders } \\
\text { - Other motorists } \\
\text { - Bus passengers } \\
\text { - Unrestrained passengers } \\
\text { - Passengers of roof of bus/ } \\
\text { train }\end{array}$ & $\begin{array}{l}\text { - Impact with vehicle } \\
\text { - Impact with bridge } \\
\text { - Rollover } \\
\text { - Suicide bomber } \\
\text { - Police gunfire } \\
\text { - Smoking around spilled fuel }\end{array}$ & $\begin{array}{l}\text { - Nearby hospitals } \\
\text { - Traffic control } \\
\text { - Emergency medical services } \\
\text { - Nearby burn centers }\end{array}$ & $\begin{array}{l}\text { - Opportunity to scoop fuel } \\
\text { - Lack of corporate } \\
\text { accountability }\end{array}$ \\
\hline $\begin{array}{l}\text { Post- } \\
\text { event }\end{array}$ & $\begin{array}{l}\text { - Victim recovery } \\
\text { - Post-injury care received } \\
\text { - Psychological coping of } \\
\text { individual }\end{array}$ & $\begin{array}{l}\text { - Severity of injuries } \\
\text { - Post-event psychological } \\
\text { impact }\end{array}$ & $\begin{array}{l}\text { - Rehabilitation facility } \\
\text { - Transportation to hospitals }\end{array}$ & $\begin{array}{l}\text { - Health insurance } \\
\text { - Limited communication } \\
\text { causes delay in internation- } \\
\text { al assistance } \\
\text { - Family and social support } \\
\text { - Access to rehabilitation } \\
\text { services }\end{array}$ \\
\hline
\end{tabular}


victims in LMIC to receive improved care while trauma systems are still nascent in many developing countries.

Despite the significant trauma incurred by affected populations, the literature likely significantly underreports oil tanker disasters. This is particularly true for the academic literature as only one of 224 disasters in the last 20 years was described in a peer-reviewed journal during the study time period, and one additional study was published after the end of the study period. In the former publication, Van Kooij and colleagues described lessons learned in the oil tanker truck explosion in the rural town of Nakuru, Kenya in 2009. The authors found that in addition to the more than 100 killed, 122 injured victims with severe burns were initially cared for at the local hospital, which had meager resources to respond to such a disaster. Recommendations included better assessment of available resources, triage to higher levels of care as soon as possible for severely burned patients, and adequate analgesia for palliating patients with survivable injuries [2]. In a more recent publication, Sawyer et al. shared their personal experiences of responding to the previously described South Sudan oil tanker explosion with the organization, Save the Children. The authors comment on the improvements made in high income nations such as Australia to prevent these sorts of disasters, including but not limited to mandatory anti-roll technology, stability braking systems, and increased roadside stops to enforce traffic regulations [24]. Similar interventions have been implemented in other high income countries (HIC) such as the United States (U.S.), with a marked improvement in commercial transport fatalities (58.5\% decrease since 1990) reported by the U.S. Bureau of Transport Statistics (BTS) likely contributing to the low mortality noted there in this review [25]. Although mortality was low in the U.S. and other HIC, it bears mentioning that nearly one quarter of disasters occurred in the U.S. This can perhaps be explained by the fact that the U. S. consumes 19.6 million of the 96.5 million barrels per day used daily in worldwide, combined with the extensive highway transportation needed to deliver petroleum inland [26]. However, the data are insufficient to draw meaningful conclusions from this finding, and further investigation is merited to identify the root causes of these disasters, as well as discrepancies in reporting worldwide. A measured academic examination of the real differences between capacity and need of LMIC, and specifically the sites of oil tanker truck disasters, could also be helpful to providers in future disasters.

Although this is the only systematic review of oil tanker truck disasters, several limitations are worth discussion prior to interpreting the results. The academic literature is not well suited for reporting on these disasters. Therefore, we searched the lay literature with an inclusive strategy and did not exclude non-English reports to mitigate this limitation as much as possible. However, there are several shortcomings related to relying on the news media for information. There is likely both review-level and outcome-level bias in the handling of these resources. Because each online interface requires a slight variation on the planned search strategy (Appendix A), it is possible that results were incomplete, with the notable absence of any reports from South America pointing toward inconsistent media reporting. A general search strategy including a broader array of search terms may have captured more reports. Furthermore, the reports accessed for this study were likely subject to reporting bias from the authors, editors, and publishers, especially as these are not peer-reviewed publications. The circumstances surrounding some disasters and the reported numbers of dead and injured were widely variable. In order to address this limitation, we included the highest and most recent reports of morbidity and mortality available. These numbers tended to increase in more recent reports as missing persons were found and identified or treated, although this trend was not formally recorded as part of our data collection strategy. Additionally, reports rarely provided detailed descriptions of injuries or follow-up on victims at local hospitals. The voices of the poorest and often most affected by these disasters were not included in the majority of these reports, representing a further reporting bias. This study demonstrated that these disasters are being reported both locally and abroad, but future research into local access to media is merited to ensure this message reaches those most affected, as well as how best to prevent, prepare for, and mitigate these tragedies when they occur. Despite these limitations, this report allows general conclusions to be drawn about the epidemiology of these disasters, the health impact, and potential prevention targets.

\section{Conclusions}

In summary, oil tanker disasters are a source of considerable morbidity and mortality, especially in LMIC and in instances involving scooping. Based on available reports, we recommend the following:

- Create and implement global standards for improved highway safety and regulation of oil tanker trucks and drivers.

- Create and implement standardized emergency procedures for clearing the scene when an oil tanker truck is disabled or involved in a collision.

- Expand emergency medical transport, including training civilians to assist in disasters.

- Optimize hospital infrastructure to accommodate victims of disasters.

- Provide community education about the dangers of scooping.

- Engage petroleum companies in the communities where they procure and transport oil.

\section{Disclosure statement}

The authors have nothing to disclose.

\section{Appendix A. Electronic search strategy}

PubMed search terms: oil tanker AND truck AND fire OR explosion

Nexis Uni search terms:

1. oil tanker truck

2. NARROW BY DATE $1 / 1 / 97-8 / 14 / 17$

3. NARROW BY NEWS (checkbox) 


\section{NARROW BY fire OR explosion}

Google search terms:

1. oil tanker truck fire explosion

2. Select News tab

3. Tools

4. Custom range: $1 / 1 / 97-8 / 14 / 17$

World Health Organization Global Health Library (http://applications.emro.who.int/library/Databases/ wxis.exe/Library/Databases/iah/)

1. oil tanker truck (AND), no results

2. oil truck (AND), no results

REFER E N C E S

[1] den Hollander D, Mars M. Smart phones make smart referrals. The use of mobile phone technology in burn care-a retrospective case series. Burns 2017;43:190-4, doi:http://dx. doi.org/10.1016/j.burns.2016.07.015.

[2] Young L, Orosco R, Miller S. Double fire tragedy of Kenya. Eplasty 2009;10:c3.

[3] South Sudan oil tanker blast kills 170. BBC News; 2015 September 17. [Accessed 26 December 2017].

[4] Van Klooij E, Schrever I, Kizito W, Hennaux M, Mugenya G, Otieno E, et al. Responding to major burn disasters in resourcelimited settings: lessons learned from an oil tanker explosion in Nakuru, Kenya. J Trauma 2011;71(3):573-5.

[5] Pakistan fines Shell $\$ 2.6$ million for oil tanker explosion that killed 218. Radio Free Europe Radio Liberty; 2017 July 8. [Accessed 14 March 2018].

[6] Hundreds killed in Congo after oil tanker truck explodes. CNN News; 2010 July 3. [Accessed 14 March 2018].

[7] Brooks J. North Korea appeals for help after railway explosion. The New York Times; 2010 April 4. [Accessed 14 March 2018].

[8] Nexis uni product overview. LexisNexis. https://www.lexisnexis. com/en-us/products/nexis-uni.page. [Accessed 3 July 2018].

[9] 62 killed in bus-oil tanker collision in southern Pakistan; police blame drivers. The Indian Express; 2015 January 11. http:// indianexpress.com/article/world/world-others/57-killed-inbus-oil-tanker-collision-in-southern-pakistan/. [Accessed 18 April 2018].

[10] Nigeria tanker inferno kills over 100. BBC News; 2000 November 6. http://news.bbc.co.uk/2/hi/africa/1009336.stm. [Accessed 18 April 2018].

[11] Global status report on road safety 2015. Geneva: World Health Organization; 2015

http://www.who.int/violence_injury_prevention/ road_safety_status/2015/en/.
[12] Reynolds TA, Stewart B, Drewett I, Salerno S, Sawe HR, Toroyan $\mathrm{T}$, et al. The impact of trauma care systems in lowand middle-income countries. Ann Rev Pub Health 2017;38:507-32.

[13] Tiska MA, Adu-Ampofo M, Boakye G, Tuuli L, Mock CN. A model of prehospital trauma training for lay persons devised in Africa. Emerg Med J 2004;21:237-9.

[14] Husum H, Gilbert M, Wisborg T, Van Heng Y, Murad M. Rural prehospital trauma systems improve trauma outcome in lowincome countries: a prospective study from North Iraq and Cambodia. J Trauma 2003;54:1188-96.

[15] Kotagal M, Agarwal-Harding KJ, Mock C, Quansah R, ArreolaRisa C, et al. Health and economic benefits of improved injury prevention and trauma care worldwide. PLOS ONE 2014;9(3):e91862, doi:http://dx.doi.org/10.1371/journal. pone.0091862.

[16] Sign up to decade of action. Federal Republic of Nigeria Federal Road Safety Corps. http://frsc.gov.ng/sign-up-to-decade-ofaction. [Accessed 14 March 2018].

[17] Onuoha FC. Why the poor pay with their lives: oil pipeline vandalisation, fires and human security in Nigeria. Disasters 2009;33(July (3)):369-89.

[18] Bell JL, Taylor MA, Chen G, Kirk RD, Leatherman ER. Evaluation of an in-vehicle monitoring system (IVMS) to reduce risky driving behaviors in commercial drivers: comparison of in-cab lights and supervisory coaching with videos of driving behavior. J Safety Res 2017;60:125-36, doi:http://dx.doi.org/ 10.1016/j.jsr.2016.12.008.

[19] Carlson LC, Rogers TT, Kamara TB, Rybarczyk MM, Leow JJ, Kirsch TD, et al. Petroleum pipeline explosions in sub-Saharan Africa: a comprehensive systematic review of the academic and lay literature. Burns 2015;41:497-501.

[21] Ahmad M, Shahid Hussain S, Ibrahim Khan M, Malik SA. Experience of burn injuries at the Pakistan Institute of Medical Science, Islamabad, Pakistan. Ann Burns Fire Disasters 2007;20 (March (1)):7-10.

[22] Charles AG, Gallaher J, Cairnes BA. Burn care in low- and middle-income countries. Clin Plast Surg 2017:44:479-83.

[23] Davé DR, Nagarjan N, Kanner JK, Kushner AL, Stewart BT. Rethinking burns for low \& middle-income countries: differing patterns of burn epidemiology, care seeking behavior, and outcomes across four countries. Burns 2018:44:1228-34.

[24] Sawyer OH, Roberts AH. Fuel tanker fire disaster-South Sudan experience. Burns 2018;44(5):1235-9.

[25] Fatality rates for select highway modes of yransportation: 1990-2015. Bureau of Transportation Statistics. United States Department of Transportation. https://www.bts.gov/content/ fatality-rates-select-highway-modes-transportation-19902015. [Accessed 29 October 2018].

[26] International oil transportation. $2017 \mathrm{https} / / /$ transportgeography.org/?page_id=6757 [Accessed 29 October 2018]. 